\title{
Identifying and Structuring the Factors Affecting Sustainable Banking Resources with Using Interpretive Structural Modeling
}

\author{
MOUSAVI Seyed Mahdi ${ }^{10}$, YAMOULA Alireza ${ }^{11}$, \\ KHOSHROO Mohsen ${ }^{12}$
}

\begin{abstract}
Considering the recent developments in banking system, banks are able to increase their power of partnership in different areas of manufacturing, industrial, agricultural and else by attracting more resource approach, and creating competitive advantage, which result in expansion and increase of earnings or benefits of the bank as well as creating competitive advantage. Considering the limitation on resources and time, the ability to jointly invest in all of the influential factors on creating sustainable banking resources cannot be achieved. The main aim of the present research is to provide a model of the influential factors on creating sustainable banking resources so with usage of which, managers can identify the factors that have the highest influence on the others and plan on the them. For this purpose, 10 influencing factors on creating sustainable banking resources such as financial risks, amount and quality of equity, amount of assets, etc. by taking into account the relevant studies as well as benefiting from specialist's opinions are chosen. Then the influential structure of these factors with usage of interpretive structural modeling method is drawn. The obtained results show that management of equities and human resources, are the most influential factors on providing sustainable banking resources.
\end{abstract}

Keywords: Sustainable Banking Resources, Equity \& Asset Management, Interpretive Structural Modeling

JEL: E50

UDK: 005.336.1:336.71

005.52:330.14

COBISS.SR-ID 253493516

\section{Introduction}

The extremely heavy responsibility of banking system on economy based on market is not hidden from the public eye and is continuously one of the important parts of country's economy which directly impacts on the growth or depression of economic structure with its activity.

Because the available assets in banks are the main resources for purchasing products and services, also given loans are the resources for creating credit for all of the economic units such as families, jobs, companies, and government. Therefore, banks' better activities and usage of practical marketing tools for the purpose of fulfilling their goals such as return on the assets and equipping the same will have an impact on different economic activities and generally the

\footnotetext{
${ }^{10}$ Islamic Azad University, Arak Branch, Iran, mahdi.moussavi@yahoo.com

${ }^{11}$ Islamic Azad University, Naragh Branch, Iran, alirezayamola@yahoo.com

${ }^{12}$ Islamic Azad University, Naragh Branch, Iran, m.khoshru@gmail.com
} 
whole of the economic situation (Safaeian \& Venus, 2005). In banking system, implementing the affairs as fast as possible and not wasting any time are considered as the most important successful elements in banking competition, and customers as the main determining parts of this competition value the speed and improved technology to a large extent. Banking these days require innovative methods, effective customer care, providing practical technology and proper customer requirement fulfillment and services which shows that each bank that is more successful in these affairs will be also successful in attracting more resources in the competitive market and consequently permanent durability and therefore more returns (Jafarpour \& Amadeh, 2009). Usually, attracting financial resources are of high priority in banking activities, because success in this field can be effective on being successful in other fields and areas.

Attracting financial resources in each bank depends on both internal and external affairs, therefore knowing these factors and the amount of influence that each of them has in order to succeed in this area is very much fundamental and important. In the whole world nowadays attracting financial resources is so important and vital to the banks that there has been a creation of great competition amongst them. A very obvious and main witness to this issue is providing updated and innovative services for achieving trust and attention of people to invest in banks.

Therefore, in the recent few decades, new grounds are made for attracting more banking resources and providing better and faster services to the customers. As a result, it's imperative that we have a better and more practical use of these resources by investigating different influential factors on attracting banking resources (Rahnamai et al., 2012). The implemented surveys show that banks invest their own investments on buildings and skyscrapers as well as commercial and luxury complexes via their own established companies that act as brokers and middle companies. In the other words, they act by choice in housing sector and transfer part of their investment to the trading sector. International relations between countries have developed to a large scale that use of one unified word should be taken into account as a world Stock Exchange for the whole exchanges around the world. These worldwide markets are webbed together and are affected by each other. It's obvious that the country that has more flexible and logical rules and regulations in terms of foreign investment has better chance and attraction for a foreign investor. Development of sustainable banking resources with consideration of the main role of the banks on economic expansion has a special importance. Banks play a key role in decreasing inflation, economic expansion with usage of providing financial and credential aids, playing the middle role in communicating amongst economic agencies both internal and foreign, exit from depression by expanding small and middle-sized agencies and other issues.

As a result, in order to expand sustainable banking resources, there is a need to identify the influential factors on it to plan and improve these factors and provoke them so to achieve better sustainable banking resources. Considering the time, ability, and expenses of each organ, it cannot be expected that managers and system planners can have all of the influential factors under control at the same time. In any case there are a lot of limitations that managers of organizations face. Considering the recent changes in banking system, the bank of City Bank has drawn the attention of high experts and managers by using the resource attracting approach as well as making the benefit of competition in this bank, because attracting banking resources results in partnership of the bank in different areas of manufacturing, industrial, agricultural and else and this issue will result in expansion of the bank as well as profit making and also making the benefit of competition. Therefore, the purpose of this research is to identify the influential factors on attracting sustainable resources at City Bank branches and then providing the effective module of these factors in order to improve the decision-making conditions of the managers of the bank by using the interpretive structural modeling method. 


\section{Literature review}

\section{Concepts \& theories}

\section{Banking system}

Monetary and banking system together count as one of the main pillars of governmental interference in economic affairs because of its role in determining monetary issues on economy and importance of banking organizations in managing the amounts. Monetary and banking pillars along with budget and planning pillars provide an important economic power in the possession of government, which in accordance to the government nature; can influence the society's whole economy. Money as a tool for evaluating the value of commodity and services, a tool for payments, trading as well as being a tool for saving and accumulating the values is counted as an important tool for economy development (Masoud \& Ashraf, 2012).

\section{Sustainable Banking Resources}

In a not very far past the major part of banks' earnings were made as a result of paid facilitations but in the past recent years more than 50 percent of European countries as well as USA's income of the banks were made from banking services and fees. Banks have been able to reduce their earnings' dependency on interest rates which comes along with high levels of fluctuations by, successfully using this method and on the other hand reduced interest rates on facilitations and also reduced gap between receiving and paying interest rates or marginal profits to less than 2 percent. These days most of the services such as money transfer, getting money out of ATM machines, cheque deposit and foreign exchange services are subject to banking fees. This change is also favored and satisfactory by bank customers because even if investing in banks is less than a certain number then is subject to fees and for those who seldom use cheque as a payment method have less cost. Instead they get paid the profit for current investment. Consequently, banks for the purpose of expanding their activities look for long lasting resources for themselves in order to benefit from competition advantages. Meaning that like interest-free investment which was once a suitable resource for banking activities and now is neither suitable nor sustainable, banks should take other measures and changes into account for attracting resources (Masoud \& Ashraf, 2012). In the following there will be more explanation on each sustainable banking resource.

\section{Equity Management}

Equity management is referred to a collection of system and methodical process for keeping, using, and expansion of bank equity. Management of equity - debt is an effort to match equities and debts in relevance to credits and their sensitivity towards the interest rates and fundamentally risks of liquidity and interest rates that are resulted from this non-compliance of the two. In this framework generally, there will be a combination of engineering methods with experience and theoretical economy with completion of which there will be a creation of a tool that will be used in harmony and with logical process for future decisions. In the other words, equity management specifies a framework for designing and delivering long or short-term plans of a group. Simply the aim of this act is to increase benefits and profits of a group in order to advance its defined purposes on the basis of available facilities and resources.

This method combines the economic evaluation on the levels of projects' investment management, network and systematic. Achieved information of this method helps the decision making in future profitable investments of the group (Karimzadeh, 2013). 


\section{Human resources}

Expansion of human resources in a bank means creation of ideas and thoughts by the employees of that organization and the new meaning of it requires the employees to equip with qualities and skills in banks so that they can provide their abilities, energy, expertise and their thought for the purpose of fulfilling organizations mission with total enthusiasm and continually creating new values of both intellectual and qualitative.

In new concept, human resource development in banks has the following components;

- Creating scientific awareness and increasing the knowledge of employees.

- Producing scientific and balanced behavior in employees.

- Creating added value as a quality in employees.

- Increasing abilities in employees.

- Development of skill of implementing jobs.

- Updating employee information.

- Ability to solve in a scientific way.

- Correct way of implementing jobs.

- Rational decision making.

- Harmonic character growth in employees.

- Ability to combine information and creating new groups (Davami \& Haghighi, 2012), (Khodadadi et al., 2011).

\section{Equity Quality}

Since banks have to make decisions for the purpose of allocating the investments made available at their disposal, the decision forms their level of credit risk and exceptions.

Therefore, with criteria such as checking the banks equity quality which include loans and bonds of the banks we can achieve a dimension of these aimed assessments. With consideration of the equity quality importance, presentation of the following categories which are also the categories of United States' bank equity can be provided;

- Capacity; Loaners ability of payment.

- Deposit; Equity quality of the loan bankroll.

- Conditions: Situation and conditions on which the necessity for loan is created.

- Asset: Difference between equity value of the loaners and their debts.

- Nature: Tendency of the loaners to repay the loans, which are evaluated on the basis of their previous payments of loans and credit. (Paltayian et al., 2012).

\section{Financial Risks}

Financial risks can affect credit and value of the banks to a large scale. For the purpose of decreasing the financial risks, banks should use modern methods of managing financial risks (Mirtabar Darzi, 2011).

\section{Operational Productivity}

Operational productivity of banks is possible via operational budget allocating, improvement of working methods as well as internal procedures. Also, one of the most important duties of organizations high management and human resources is to determine the duties of each section for the purpose of getting to the main aim of the organization. In determination of these duties, the position of the organization and human resources and the process of each of these units and the sub-sectors of the organization are specified and the design of the strategic plan is drawn. With usage of the strategic plan drawing, the possibility to check and prioritizing the strategic aims with each other, duties of each employee, obstacles, 
evaluation and measure as well as feedback of the mentioned process can be prepared (Masoud \& Ashraf, 2012).

\section{Equity Amount}

The amount of equity in increasing assets and successful implementation of bank's plans has a direct effect. For this purpose, the bank should try to increase the foreign and internal equities (Davami \& Haghighi, 2012).

\section{Asset Amount}

The experts believe that one of the necessary conditions for a healthy performance and guarantee on sustainable operations of banks or credit institutions is having appropriate assets.

Asset provides the possibility to the bank to be properly protected and covered when faced with possible and unpredicted losses and also protect the investors in case of possible losses and consequently increase the public trust towards the bank (Karimzadeh, 2013).

Although in accordance to the beliefs of banking system activists, banks increase of assets will result in improvement of working and trading environment as well as economic conditions, also will strengthen the manufacturing and industrial sectors of the country and will increase the production and decrease unemployment along with it, but it seems in conditions that any increase of assets that result in irregular fluctuation rates, compensation of liquidity shortage of banks are more logical with consideration of the following ways. (Karimzadeh, 2013).

\section{Liquidity}

Nowadays, liquidity management is one of the biggest challenges that the banking system is facing. The main reason for this challenge is that majority of banking resources are provided from short term deposits. Additionally, vested facilitations of banks are spent on investing in equities that have lower degree of liquiditation. For better and right management of liquidity, it's imperative that proper tools and effective factors for this purpose are rightfully identified.

One of the most important influential factors on bank's liquidity is the equity position and bank's debts. On the other hand, management of equity-debt is one of the key factors in expressing the financial stability of banking and economy (Kamarolzaman \& Madun, 2013).

\section{Deposits}

Increase in bank deposits can result in increase of banks equities. There are many solutions for increasing bank deposits which include effective advertising, providing financial aids, leisure services and from distance, providing modern and new banking services (Davami \& Haghighi, 2012).

\section{Absorbing Rate of Financial Losses}

Absorbing financial losses will give the assurance to the customers and account owners so that in case the financial risks occur, the possibility of absorbing these losses by banks is available. The increase of absorbing rate of financial losses via substitute investments and advertisement of the same in order to increase the banking deposits can be beneficial (Masoud \& Ashraf, 2012). 
Table 1. Sustainable Banking Resources

\begin{tabular}{|c|c|}
\hline Identified Factors & Resource \\
\hline Financial Risks & Mirtabar Darzi, 2011; Masoud \& Ashraf, 2012 \\
\hline Equity Amount & Davami \& Haghighi, 2012; Masoud \& Ashraf, 2012 \\
Losses & Masoud \& Ashraf, 2012; Karimzadeh, 2013 \\
\hline $\begin{array}{c}\text { Absorbing Rate of Financial } \\
\text { Asset Amount }\end{array}$ & Masoud \& Ashraf, 2012; Karimzadeh, 2013 \\
\hline Operational Productivity & Masoud \& Ashraf, 2012; Karimzadeh, 2013 \\
\hline Equity Quality & Masoud \& Ashraf, 2012; Karimzadeh, 2013 \\
\hline Management of Equities & Masoud \& Ashraf, 2012; Karimzadeh, 2013 \\
\hline Liquidity & Masoud \& Ashraf, 2012; Kamarulzaman \& Madun, 2013 \\
\hline Deposits & Davami \& Haghighi, 2012; Masoud \& Ashraf, 2012 \\
\hline Human resources & Khodadai et al., 2011; Davami \& Haghighi, 2012; Masoud \& Ashraf, \\
\hline
\end{tabular}

\section{Research Background}

Karimzadeh (2013) in an article "Surveying the influential factors on plenishing banking resources from the Bank Refah branches of Isfahan managerial point of view" expressed that this study will consider the effective factors on providing resources on the basis of importance and priority at branches of Refah Banks of Isfahan. The achieved results of this research indicated that all of the five considered factors in research were effective in plenishing resources at Refah bank branches were more than medium limit. Service, communication and human resource factors, physical factors, financial factors and organizations dependency factors respectively were the influential factors for attracting resources.

Rahnamai et al., (2012) in an article called "Surveying the influential factors on plenishing banking resources from the Bank Melli branches of Mazandaran province managerial point of view" expressed that this study will consider the effective factors on providing resources on the basis of importance and priority at branches of Melli Bank at Mazandaran province branches.

The achieved results of this research indicated that all of the five considered factors in research were effective in plenishing resources at Melli bank branches more than medium.

Masoud \& Ashraf (2012) in their study concentrated on the effective factors on profitability in Islamic banks. They expressed that some of the effective sources on creating sustainable banking resources are financial risks, equity amount, absorbing rate of financial losses, amount of assets, operational productivity, equity quality, management of equities, liquidity, deposits and human resources. They also surveyed the Marco-economic components such as monetary politics, liquidity, etc. and their effect on Islamic banks' profit making. Results of their research pointed to the effect of mentioned sources on creating sustainable banking resources.

\section{Research Method}

In this research for the reason and nature of the subject and in compliance with research predictions, the use of expressional-geodesic research method is taken into account.

Considering that one of the aims of the research is to use the found results for solving the current subject issues in banking industry, then this is an applicable research and on the other hand has a fieldwork nature, meaning that major part of information is gathered by managers and experts in a form of questionnaire. Therefore, it can be summed up that the method of this research is of an expressional-geodesic and positioned in framework of applicable research.

\section{Expert Population}

For the purpose of determining the level and prioritizing the identified factors, there has been usage of expert opinions of 25 of the professionals and specialists in the field of banking and financing and also university professors. Because of the limitations in expert population, 
the usage of all the expert opinions was considered and in fact there was no sampling. The experts of this group include 18 men and 7 women, whom are actively working with positions at Tehran university science board and the authorities of City Bank of Qom. Amongst them, 6 have $\mathrm{PhD}$ in different fields, 13 have Master Degree and other have University Degree and with high levels of experience in banking services.

\section{Method and Tool for Collecting Information and Data}

In order to collect and analyze data and information of this research, there's been usage of various methods and tools which in the following will be divided in relevance to different needs of the research model.

Library studies to identify the effective factors on sustainable banking resources.

The interpretive structural modeling questionnaire for the purpose of checking the effectiveness level of each factor. This questionnaire is special for interpretive structural modeling method that in the following will be looking at its design method. In this questionnaire, coupling comparison between 2 variables or factors will be specified and the method of their effect on the basis of 4 possible forms will be determined (Azar et al., 2013).

\section{Analysis of Data}

For the purpose of dividing and analyzing the gathered data, the usage of interpretive structural modeling (ISM) is taken into consideration for which we will continue to provide the method in the following:

Firstly, the main effective factors on creating sustainable banking resources at City Bank branches in Qom which are extracted from articles, studies, and examination of expert opinions.

Then by using the matrix questionnaire of interpretive structural technique which will be spread amongst experts, coupling comparison between each couple factors will be done and eventually by using this technique sequence and also leveling of these factors to be done. In the end also by using division and analysis (MICMAC) the power of guiding and dependency of the factors will be checked.

ISM technique and achieving the internal relations and priority of elements in a system should be process covered. Primary stages and general framework of this work is in accordance to the picture. Now with using this picture and checking the subject literature in this regard, we can name the stages of implementing the ISM technique as follows (Azar et al., 2013).

\section{Entering Variables}

Interpretive structural modeling starts by identifying the variables that are related to the subject matter. In the present research we are looking to find the relation between the effective factors on creating sustainable banking resources at City Bank branches in Qom by using the interpretive structural modeling, therefore the first step should be to identify these factors via subject literature.

\section{Achieving Internal Relations of Matrix Structure}

This matrix is a matrix with variable dimensions, variables of which will be expressed respectively on the first row and column. Then relations between coupling variables will be specified with symbols. To determine the type of relations we can use the expert opinions whom can be managers or experts of the considered industry. The general picture of this matrix is as the following: 


\begin{tabular}{|c|l|l|l|l|}
\hline Variables & 1 & 2 & $\ldots$ & $\mathrm{M}$ \\
\hline 1 & & & & \\
\hline 2 & & & & \\
\hline$\ldots$ & & & & \\
\hline $\mathrm{M}$ & & & & \\
\hline
\end{tabular}

To determine the type of relation the following symbols can be used;

$\mathrm{V}$ : Variable i (Row) helps to reach to variable j (Column).

A: Variable $\mathrm{j}$ (Row) helps to reach to variable i (Column).

$\mathrm{X}$ : Variables i \& $\mathrm{j}$ help to reach each other (Two-way relations).

O: Variables i \& $\mathrm{j}$ have no relations with each other.

\section{Achieving Accessing Matrix}

By converting symbols of matrix relation (SSIM) to numbers of zero and one considering the following rules, accessing matrix can be reached. These regulations are as follows:

A) If square ( $i, j$ ) in matrix (SSIM) got $\mathrm{V}$ symbol then related square in accessing matrix will get number 1 and the opposite square of it $(\mathrm{j}$, i) will get the number 0 .

B) If square $(i, j)$ in matrix (SSIM) got A symbol then related square in accessing matrix will get number 0 and the opposite square of it $(\mathrm{j}, \mathrm{i})$ will get the number 1 .

C) If square $(i, j)$ in matrix (SSIM) got $X$ symbol then related square in accessing matrix will get number 1 and the opposite square of it $(\mathrm{j}, \mathrm{i})$ will get the number 1 .

D) If square $(i, j)$ in matrix (SSIM) got $\mathrm{O}$ symbol then related square in accessing matrix will get number 0 and the opposite square of it $(\mathrm{j}, \mathrm{i})$ will get the number 0 .

\section{Adjusting Accessing Matrix}

After the first accessing matrix is achieved then the internal adjustment should be established. For example, if variable 1 results in variable 2 and variable 2 results in variable 3 then variable 1 should result in variable 3 and if such situation was not established in accessing matrix then the corrected matrix and the missed relations should be substituted.

\section{Determination of Level and Priority of Variables}

In order to determine the level and priority of variables, collection of accessibles and collection of pre-requirements for each variable will be determined. Accessible collection of each variable consists of variables which can be reached via this variable and pre-requirement collection consists of variables via which can reach this variable. This act can be done by using accessing matrix. After determination of accessible collection and pre-requirement for each variable, the joint elements of both collections for each variable will be identified. The result of this action will be as the following table:

\begin{tabular}{|c|l|l|l|l|}
\hline Elements & Accessing Collection & Pre-Requirement Collection & Overlapping elements & Level \\
\hline 1 & & & & \\
\hline 2 & & & & \\
\hline$\ldots$ & & & & \\
\hline $\mathrm{N}$ & & & & \\
\hline
\end{tabular}

After determining collections of accessing and pre-requirement and joint elements, it is time to determine the level of variables (Elements). In the first table, the variable has the highest level that it's accessing collection and joint elements are equal. After determination of this variable or variables, they will be eliminated from the table and with the rest of the variables we will form another table. In the second table also like the first table we will specify the second 
level variable and we will continue these actions until the level of all the variables are determined.

\section{Diagram Drawing}

After determining levels of variables, its time to draw the diagram of relations and levels of variables. Primarily on this basis of variable levels, we will draw them on the basis of priority and from top to bottom on circles and then on the basis of compatible accessible matrix, the relations between variables and the pointing line will be specified.

\section{Division \& Analysis (MICMAC)}

This model will address the variables analysis on the basis of their influential power and dependency. Thus, the amount of power will be placed on the horizontal diagram and the amount of dependency will be placed on the vertical diagram and the amount of power and influential dependency appear on the diagram like coordinates (Azar et al., 2013). Then on the basis of influential power and dependency, 4 areas will be made on diagram. The place where both effect and dependency are low, the place where both effect and dependency are high, the place that effect is low but dependency is high, and eventually the place where effect is high and dependency is low. Therefore, each variable is placed in one area and on the basis, that, where in which area it's present, a different approach should be made on that variable. The first group consists of autonomous variables (Area 1) which have weak power of influence and dependency. These variables to some extent are separate from other variables and have lesser relations. The second group consists of dependent variables (Area 2) which have weaker influential power but high levels of dependency. The third group is the linked variables which have high levels of influential power and dependency. In fact, any action on these variables will result in changes on the other variables. The fourth group is the independents (Area 4). These variables have high levels of influential power and low dependency. The variables that have high levels of influential power are expressly called Key Variables. It is obvious that these variables are placed in either groups of independent variables or linked. By adding the inputs of " 1 " on each row and column, the influential power and the amount of dependency will be achieved. On this basis the diagram of influential power-dependency is drawn (Azar et al., 2013).

\section{Research Findings}

After the 10 fundamental effective factors on development of sustainable banking resources were identified, the interpretive structural modeling questionnaire was handed to experts and they were requested to specify the relation between these factors. In accordance to experts' definition and for specifying the relation between them, four options were made available to them. First was that the factor A will have an effect on factor B. Second was that the factor B would have an effect on factor A. Thirdly was that both factors would have an effect on each other and fourthly was that there was no relation between the two factors. A request was made to each expert to compare factors by coupling. If the row factor is a pre-requirement for column factor and this relation is shown by $\mathrm{V}$. If the column factor is a pre-requirement for row factor and this relation is shown by $\mathrm{A}$. If both factors need each other, this relation would be shown by $\mathrm{X}$ and if they don't need each other than the relation would be shown by O. Experts then considering their knowledge and experience specified the relations between the influential factors on creating development of sustainable banking resources. 


\section{Results of Opinion Polling from Experts on Variable Relations}

After collecting all of the questionnaires, expert opinions were gathered. Totality of opinions was done on the grounds of frequency. For this reason, the numbers of 1 to 4 were given to each of the 4 relations. Number 1 related to the one without relation $(\mathrm{O})$. Number 2 relates to mutual needs and joint relations $(\mathrm{X})$. Number 3 related to the relation of column to row (A) and number 4 related to the relation of row and column (V). Then averaging was done.

If the resulted number was between 1 and 2 without relation, between 2 and 3 mutual needs, between 3 and 4 relations of column on row, and when between 4 and 5 then relation of row on column was considered. Eventually, result of opinions was calculated which is shown on the table 2 .

\section{Forming the Primary and Final Accessing Matrix}

In accordance to provided explanations, in table 3 the relation between 1 and 6 is specified by $\mathrm{V}$. V means that row is a pre-requirement of column. Meaning that factor number 1 is a prerequirement to factor number 6 and effects on it. For this purpose, in the eighth square of first row the number 1 and on the first square of sixth row the number 0 are placed. Also, relation between 1 and 9 is specified by letter $\mathrm{O}$, meaning that there is no relation between the two factors and none are the pre-requirements of the other. Therefore, the number 0 should be placed in the ninth square of first row and first square of ninth row. In the following table all of the specified relations are entered by number.

After the primary matrix is achieved, its internal compatibility should be maintained. For example, if variable 1 results in variable 2 and variable 2 results is variable 3 then its imperative that variable 1 results in variable 3 and if in the final accessing matrix of this relation was not maintained, then the corrected matrix and the missed relations should be substituted. In the final matrix the amendments are shown by $1^{*} .1$ is pre-requirement of 4 and 4 is pre-requirement of 6 . So therefore 1 should surely be pre-requirement to 6 . However, in the previous table and in the sixth square of first row number 0 is inserted. In the next table this relation is amended.

Meaning that instead of number 0 , number $1^{*}$ is inserted. This relation is calculated for all of the factors separately and anywhere there was a need for correction, this amendment was done manually by hand (table 4). 
Table 2. Result of Opinion Poll on Variables Relations

\begin{tabular}{|c|c|c|c|c|c|c|c|c|c|c|}
\hline & 10 & 9 & 8 & 7 & 6 & 5 & 4 & 3 & 2 & 1 \\
\hline 1 & $\mathrm{O}$ & $\mathrm{V}$ & $\mathrm{V}$ & $\mathrm{A}$ & $\mathrm{A}$ & $\mathrm{V}$ & $\mathrm{V}$ & $\mathrm{V}$ & $\mathrm{V}$ & \\
\hline 2 & $\mathrm{~V}$ & $\mathrm{~V}$ & $\mathrm{~V}$ & $\mathrm{~A}$ & $\mathrm{O}$ & A & $\mathrm{V}$ & $\mathrm{O}$ & & \\
\hline 3 & $\mathrm{O}$ & $\mathrm{V}$ & $X$ & A & A & A & A & & & \\
\hline 4 & $\mathrm{~V}$ & $\mathrm{~V}$ & $\mathrm{~V}$ & A & $\mathrm{V}$ & $\mathrm{O}$ & & & & \\
\hline 5 & A & $\mathrm{V}$ & $\mathrm{V}$ & A & $\mathrm{V}$ & & & & & \\
\hline 6 & $\mathrm{O}$ & $\mathrm{V}$ & $\mathrm{V}$ & A & & & & & & \\
\hline 7 & A & $\mathrm{V}$ & $\mathrm{V}$ & & & & & & & \\
\hline 8 & $\mathrm{O}$ & $X$ & & & & & & & & \\
\hline 9 & $\mathrm{O}$ & & & & & & & & & \\
\hline 10 & & & & & & & & & & \\
\hline
\end{tabular}

Table 3. Formation of the Accessing Matrix

\begin{tabular}{|c|c|c|c|c|c|c|c|c|c|c|}
\hline & 1 & 2 & 3 & 4 & 5 & 6 & 7 & 8 & 9 & 10 \\
\hline 1 & 1 & 1 & 1 & 1 & 1 & 0 & 0 & 1 & 1 & 0 \\
\hline 2 & 0 & 1 & 0 & 1 & 0 & 0 & 0 & 1 & 1 & 1 \\
\hline 3 & 0 & 0 & 1 & 0 & 0 & 0 & 0 & 1 & 1 & 0 \\
\hline 4 & 0 & 0 & 1 & 1 & 0 & 1 & 0 & 1 & 1 & 1 \\
\hline 5 & 0 & 1 & 1 & 0 & 1 & 1 & 0 & 1 & 1 & 0 \\
\hline 6 & 1 & 0 & 1 & 0 & 0 & 1 & 0 & 1 & 1 & 0 \\
\hline 7 & 1 & 1 & 1 & 1 & 1 & 1 & 1 & 1 & 1 & 0 \\
\hline 8 & 0 & 0 & 1 & 0 & 0 & 0 & 0 & 1 & 1 & 0 \\
\hline 9 & 0 & 0 & 0 & 0 & 0 & 0 & 0 & 1 & 1 & 0 \\
\hline 10 & 0 & 0 & 0 & 0 & 1 & 0 & 1 & 0 & 0 & 1 \\
\hline
\end{tabular}

Table 4. Formation of Final Accessing Matrix

\begin{tabular}{|c|c|c|c|c|c|c|c|c|c|c|c|}
\hline & 1 & 2 & 3 & 4 & 5 & 6 & 7 & 8 & 9 & 10 & Penetration \\
\hline 1 & 1 & 1 & 1 & 1 & 1 & $* 1$ & 0 & 1 & 1 & $* 1$ & 9 \\
\hline 2 & 0 & 1 & $* 1$ & 1 & 0 & $* 1$ & 0 & 1 & 1 & 1 & 7 \\
\hline 3 & 0 & 0 & 1 & 0 & 0 & 0 & 0 & 1 & 1 & 0 & 3 \\
\hline 4 & $* 1$ & 0 & 1 & 1 & $* 1$ & 1 & $* 1$ & 1 & 1 & 1 & 9 \\
\hline 5 & $* 1$ & 1 & 1 & $* 1$ & 1 & 1 & 0 & 1 & 1 & $* 1$ & 9 \\
\hline 6 & 1 & $* 1$ & 1 & $* 1$ & $* 1$ & 1 & 0 & 1 & 1 & 0 & 8 \\
\hline 7 & 1 & 1 & 1 & 1 & 1 & 1 & 1 & 1 & 1 & $* 1$ & 10 \\
\hline 8 & 0 & 0 & 1 & 0 & 0 & 0 & 0 & 1 & 1 & 0 & 3 \\
\hline 9 & 0 & 0 & $* 1$ & 0 & 0 & 0 & 0 & 1 & 1 & 0 & 3 \\
\hline 10 & $* 1$ & $* 1$ & $* 1$ & $* 1$ & 1 & $* 1$ & 1 & $* 1$ & $* 1$ & 1 & 10 \\
\hline Dependence & 6 & 6 & 10 & 7 & 6 & 7 & 3 & 10 & 10 & 6 & \\
\hline
\end{tabular}




\section{Drawing Model and Diagram}

After determination of levels and assignment of influential factors, the final research model is drawn as below.

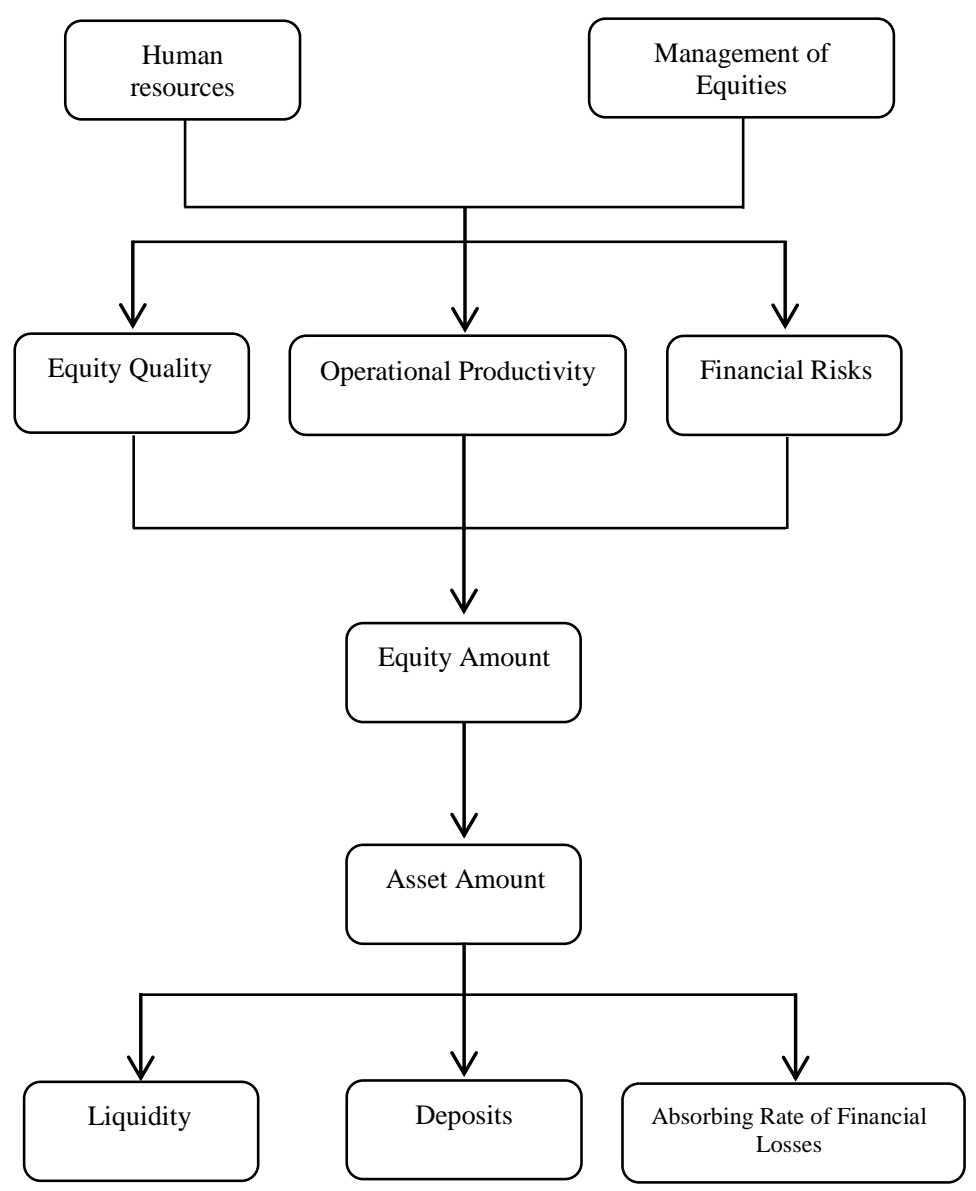

Fig. 1. Final five-dimensional model of influential factors on creating development of sustainable banking resources

\section{MICMAC Diagram}

The aim of analyzing MICMAC is to recognize and analyze the influential power and dependency between factors. Factors are divided into 4 categories depending on their influential power and dependency. The first category includes independent factors which have weak influential power and dependency. These factors are rather un-attached to the system and have weak and low relations with the system. Dependant factors are the second category which have low influential power but high dependency. Third category is the attached factors which have high influential power as well as dependency. These factors are unsustainable because any alteration in them can affect the system and in the end outcome of the system can also change these factors again. Fourth category includes independent factors which have strong influential power but weak dependency.

After the 6-surfaced model is defined, the diagram of influential power-dependency is drawn as per figure 2 . 


\section{Description of areas in diagram}

\section{Autonomous Zone}

Criteria that possess weak influential power and dependency. These variables almost detach from the model, because they have weak connections to the model. Amongst the surveyed factors, there is no factor placed in this area.

\section{Dependent Zone}

These are variables which have weak influential power but strong dependency. These dimensions in general consist of factors for creation of which, a lot of factors are interfered and they themselves can seldom pave grounds for other variables.

Liquidity, deposits, and the absorbing rate of financial losses are placed in this area. These three factors are also placed at the lowest level of effectiveness. Meaning that there are a lot of factors priory required for occurrence of these three factors and these factors themselves have less effect on the other factors.

Fig. 2. MICMAC Diagram

\author{
Linkage Zone
}

Independent Zone

\section{Dependent \\ Zone}

\section{De \\ pen \\ den \\ ce}

\section{Penetration}

\section{Linkage Zone}

Variables that have high influential power and dependency are placed in this area. Variables that are put in this area are not sustainable. Any change that is done on them, both on them and other variables has direct affect. Most of the factors meaning 6 factors are placed in this area.

By looking at this model can understand that these factors are placed in the middle of the model. The available factors on these levels can both be affected or influenced. Both the previous level of factors are pre-requirements to this level as well as these factors themselves that are pre-requirements for occurrence of next level. Therefore, the influential power on the next levels and dependency on previous levels in these factors are high. Of course, the human resources factor is also amongst them which is placed on the first level of model and its influence is equal to 10 but its dependency is also equal to 6 .

\section{Independent Zone}

Factors that have high influential power but low dependency are placed in this area. These factors along with linked factors are key variables that form the foundation of the model and for the system to start working these issues have to be paid attention to in the first place (Attri et al., 2013). The equity management factor is the only one in this area. The factor that is present on the first level and is also a pre-requirement for occurrence of other factors. This factor has 
the highest influential power amongst other factors and should be considered as the most important factor in the model, occurrence of which can have high affect in occurrence of other factors.

\section{Conclusions and Discussions}

Development of sustainable banking resources has special importance considering the key role of banks in expansion of economy. Banks also play and have a key role in reduction of inflation, economy development with usage of providing financial and credential aids, middle party role or brokers in establishing communication with domestic and foreign economic agencies, exit from depression by development of small and middle-sized agencies and other issues. Thus, in order to develop sustainable banking resources, it is necessary to identify the effective factors on it so by planning to improve those factors and provoking them, improved sustainable banking factors can be achieved. Considering time, ability, and expenses of each organization, we cannot expect that managers and planners at the same time control all the influential factors. In any case there are many limitations that the managers of organizations face. For this purpose, a list of most important and influential factors was identified so the manager by holding this list can plan for the most important an influential factor and therefore with consideration of available limits in the system, can achieve the best result. In this respect and for better understanding of what factors have explanation effects on creation of sustainable banking resources and how their relations to each other are, different studies were done and benefits were achieved from opinions of experts and specialists. Also, a 5-surfaced model was drawn which gave the possibility to the bank managers to amongst the surveyed and checked factors, they identify the most effective factors and in order to improve their condition, they employ some applications. Also in continuation some of the researched practical suggestions were given to managers and authorities;

For the purpose of improving equity management in banks, system of equity management can be used.

Steps of establishment and exploitation of the equity management system include:

1-Production of base for data and information of equities:

Before managing the equities, there is a need for awareness of all of the related information on equities.

2-Prioritization of equities;

Since normally the budget of an equity management system is limited, equities should be specified with consideration of their exploiting importance and storing, then and in accordance to that priority of source allocation.

3-Developmentof equity management plan;

In development of equity management plan, the annual storing expenditure of equities will be estimated.

4-Implementation of equity management plan;

After development of equity management plan, the equity management plan should be exploited and implemented in a processing form and by using database and information of equities and the required technology.

5-Review and revision in equity management plan;

While exploiting the equity management system, the operation and possible faults of the system will be observed and new information will be emerged which can be used for improvement of the system operation.

Solutions for development of human resources in banks:

- Educating Personnel:

Continuous training and benefiting from participation of individuals in organization has direct connection with training and flourishing the talents of personnel and can play a general role in expansion of human resources. Using different methods of training like training while 
working, distance training, participation in educational courses, seminars and conferences, using educational packages and else all can be effective.

- $\quad$ Use of Information Technology (IT):

These days providing the necessary knowledge, altering and directing the same in human resources with usage of IT is being done simply and develops personnel of an organization and society in different dimensions.

Quality of equities in a bank had direct relations with their financial operations.

Facilitation's value depends on the value of collaterals' liquidity, whereas the value of investments depends on the market value. It is expected from the bank to use sustainable equity in its portfolio and consider time managed plan in order to reduce the value of its equities and appropriate development to compensate its value.

Modern methods of managing financial risks are identified as 4 risks:

- $\quad$ Market Risks (Profit Amount, Shares, and Commodity Prices \& ...).

- Credential Risks (Repayment of Loans, Profit Fluctuations).

- $\quad$ Operational Risks (Office Corruption, System Dis-functionality \& ...).

- $\quad$ Tenure Risks (Rules \& Regulations).

Considering each one of created categories and bank situation, the risks will be identified and the management of financial risks will be directed in a way of solving them. This issue is fortified by bank consultants.

Methods of compensating bank's liquidity.

1. Fast application of banks to sell their fixed assets and allocating these assets and equities in production of country.

2. Retrieval of delayed lending, specially the large amount of it which is blocked by the hands of profiteers.

3. Necessity to amend structures in the process of decision making for allocation of loans and granting aids and facilities to production sector in line with regulations of retrieval of delayed lending.

Increase of bank deposits can result in increase of bank equities. There are different solutions for increasing bank deposits such as effective advertisement, providing financial aids, leisure services, and from distance, providing modern banking etc.

Increase of absorbing rate of financial losses by investment substitution and advertising the same to increase the amount of bank deposits can be very much beneficial.

\section{REFERENCES}

1. Attri, R., Dev, N., Sharma, V. (2013). Interpretive structural modelling (ISM) approach: an overview. Research Journal of Management Sciences, 2(2), 3-8.

2. Azar, A., Khosravani, F., Jalali, R. (2013). Soft OR: Problem Structuring Methods, Industrial Management Publication Co., $1^{\text {st }}$ edition, Tehran.

3. Davami, F., Haghighi, M. (2012). A model to improve electronic banking services through improved resources in Iran, National Congress of electronics, 2012.

4. Jafarpour, M., Amadeh, H. (2009). Examine the barriers and strategies for the development of electronic banking in the country's private banks; Journal of executive management of Mazandaran University, 9 (2), 131-149.

5. Kamarulzaman, Y., Madun, A. (2013). Marketing Islamic banking products: Malaysian perspective. Business Strategy Series, 14(2/3), 60-66.

6. Karimzadeh, S., Alimoradi Rizi, M., Habibipour, H. (2013). The factors affecting the banking Resource Mobilization: A Case Study (Prosperity Bank branches in Isfahan), TMBA Journal, 14 (1), 110-124.

7. Khodadadi V., Taker, R., Zarezadeh Mehrizi, MS. (2010). Effect of Earnings Management on the relevance of earnings and book value: compared to the long-term and short-term discretionary accruals, Journal of Financial Accounting. 
8. Masood, O., Ashraf, M. (2012). Bank-specific and macroeconomic profitability determinants of Islamic banks: The case of different countries. Qualitative Research in Financial Markets, 4(2/3), 255-268.

9. Mirtabar Darzi, A. (2011). Factors affecting the banking non-performing loans: A Case Study of Bank Sepah Mazandaran Province, Master's thesis, Faculty of Science, University of Mazandaran.

10. Paltayian, G.N., Georgiou, A.C., Gotzamani, K.D., Andronikidis, A.I. (2012). An integrated framework to improve quality and competitive positioning within the financial services context. International Journal of Bank Marketing, 30(7), 527-547.

11. Rahnemai Roodposhti, F., Heybati, F., Talebnia, G.H., Nabavi Chashemi, S.A. (2012). Present a model of corporate governance mechanisms to measure the impact on Earnings Management, Journal of Management Accounting, 15 (3) 79-100.

12. Safaeian, M., Venus, D. (2005). Marketing banking services, Negah Danesh Pub Co.

\section{Article history:}

- $\quad$ Received 15 July 2017

- $\quad$ Accepted 25 August 2017 